Revista Brasil. Bot., V.33, n.3, p.455-467, jul.-set. 2010

\title{
Diversidade e estrutura comunitária de cerrado sensu stricto em afloramentos rochosos no Parque Estadual dos Pireneus, Goiás ${ }^{1}$
}

\author{
IONA'I OSSAMI DE MOURA ${ }^{2,5}$, VERA LÚCIA GOMES-KLEIN ${ }^{3}$, \\ JEANINE MARIA FELFILI ${ }^{4 \dagger}$ e HELENO DIAS FERREIRA ${ }^{3}$
}

(recebido: 07 de fevereiro de 2008; aceito: 12 de agosto de 2010)

\begin{abstract}
Diversity and community structure of cerrado sensu stricto on rocky outcrops of the Pireneus State Park, Goiás). This study was conducted within the Pireneus State Park and its objective was to analyse the floristic composition and community structure of the woody layer of the cerrado sensu stricto on rocky outcrops and to compare with other places. The study area is located at $15^{\circ} 48^{\prime} 42^{\prime \prime}-47^{\prime \prime} \mathrm{S}$ and $48^{\circ} 52^{\prime} 40^{\prime \prime}-63^{\prime \prime} \mathrm{W}$, with average altitude of $1,310 \mathrm{~m}$. Ten $20 \mathrm{~m} \times 50 \mathrm{~m}\left(1,000 \mathrm{~m}^{2}\right)$ plots were randomly located and all woody individuals of $5 \mathrm{~cm}$ diameter at $30 \mathrm{~cm}$ from the ground level were identified and measured. Sixty five species belonging to 51 genera and 35 families were found. The richest families in species were: Myrtaceae (eight spp.), Fabaceae (seven spp.) and Melastomataceae (six spp.). The 12 species with highest VI were responsible for more than $50 \%$ of total density and dominance. The density was 1105 individuals ha ${ }^{-1}$ and basal area was $11.03 \mathrm{~m}^{2} \mathrm{ha}^{-1}$. Shannon's diversity index $\left(H^{\prime}\right)$ was 3.65 nats ind $^{-1}$. These values are high and are within the range of other studies in cerrado sensu stricto. TWINSPAN classification of the Pireneus State Park's plots showed that this cerrado is composed by species characteristics of the site like Schwartzia adamantium (Cambess.) Bedell ex Giraldo-Cañas, Alchornea triplinervia (Spreng.) Müll. Arg. and Clusia burchellii Engl., generalist species of "cerrado region" and also by species more common in gallery forests, and present similar structure to this vegetation in other edaphic conditions.
\end{abstract}

Key words - phytosociology, savanna, Serra dos Pireneus, woody vegetation

RESUMO - (Diversidade e estrutura comunitária de cerrado sensu stricto em afloramentos rochosos no Parque Estadual dos Pireneus, Goiás). Este estudo foi realizado no Parque Estadual dos Pireneus e tem como objetivo analisar a composição florística e a estrutura comunitária do componente lenhoso do cerrado sensu stricto sobre afloramentos de rochas e comparar os resultados com outros locais. A área localiza-se entre as coordenadas $15^{\circ} 48^{\prime} 42^{\prime \prime}-47^{\prime \prime} \mathrm{S}$ e $48^{\circ} 52^{\prime} 40^{\prime \prime}-63^{\prime \prime} \mathrm{W}$, a 1.310 m de altitude média. Dez parcelas de $20 \mathrm{~m} \times 50 \mathrm{~m}\left(1.000 \mathrm{~m}^{2}\right)$ foram alocadas aleatoriamente onde mediu-se todos os indivíduos lenhosos com diâmetro do tronco igual ou superior a $5 \mathrm{~cm}$, tomado a $30 \mathrm{~cm}$ do solo. $O$ estudo registrou 65 espécies, pertencentes a 51 gêneros e 35 famílias. As famílias mais representativas quanto ao número de espécies foram: Myrtaceae (oito spp.), Fabaceae (sete spp.) e Melastomataceae (seis spp.). As doze primeiras espécies em VI foram responsáveis por mais de 50\% da dominância e densidade totais. A densidade foi de 1.105 indivíduos ha- $\mathrm{e}$ a área basal 11,03 $\mathrm{m}^{2} \mathrm{ha}^{-1}$. O índice de diversidade de Shannon $\left(H^{\prime}\right)$ foi de 3,65 nats ind ${ }^{-1}$ e encontra-se dentro da faixa de variação de estudos em cerrado sensu stricto. Os agrupamentos das parcelas do parque gerados pela análise de classificação mostraram que este cerrado é composto por espécies características do local como Schwartzia adamantium (Cambess.) Bedell ex Giraldo-Cañas, Alchornea triplinervia (Spreng.) Müll. Arg. e Clusia burchellii Engl., espécies generalistas das fisionomias de cerrado e também espécies mais comuns em mata de galeria, e apresenta estrutura similar a esta vegetação em outras condições edáficas.

Palavras-chave - cerrado rupestre, fitossociologia, Serra dos Pireneus, vegetação lenhosa

\section{Introdução}

O cerrado sensu stricto com cobertura arbórea de até $60 \%$ ocorre predominantemente em Latossolos e

1. Parte da dissertação de mestrado da primeira autora, Universidade Federal de Goiás, Instituto de Ciências Biológicas, Programa de Pós Graduação em Ecologia e Evolução, Goiânia, GO, Brasil.

2. Universidade de Brasília, Programa de Pós Graduação em Ecologia, Instituto de Ciências Biológicas, Caixa Postal 04457, 70919-970 Brasília, DF, Brasil.

3. Universidade Federal de Goiás, Instituto de Ciências Biológicas, Departamento de Biologia Geral, Câmpus Samambaia (câmpus II), 74001-970 Goiânia, GO, Brasil.

4. Universidade de Brasília, Faculdade de Tecnologia, Departamento de Engenharia Florestal, Laboratório de Manejo Florestal, Caixa Postal 04357, 70919-970 Brasília, DF, Brasil.

5. Autor para correspondência: ionamoura@gmail.com
Neossolos Quartzarênicos, mas também pode estar presente sobre outros tipos de solo no Cerrado, como os Neossolos Litólicos (Reatto et al. 1998). Várias amostragens quantitativas de cerrado sensu stricto vêm sendo estudadas no âmbito do projeto Biogeografia do Bioma Cerrado (Felfili et al. 1997, Felfili \& Silva Júnior 2001, Felfili et al. 2004) e outros estudos, mas pesquisas sobre a estrutura da vegetação de cerrado sensu stricto sobre afloramentos rochosos ainda são escassas (Amaral et al. 2006, Felfili \& Fagg 2007, Miranda et al. 2007, Moura et al. 2007, Pinto et al. 2009).

Os Neossolos Litólicos são solos rasos, e por isso a penetração do sistema radicular das plantas é difícil, sendo que o estabelecimento de plantas arbóreas nesses solos ocorre apenas quando estas encontram fendas entre 
as rochas (Reatto et al. 1998). Os referidos autores estimam que esses solos ocorram em 7,3\% do Cerrado e têm como vegetação natural predominante o campo rupestre e o cerrado rupestre.

Nas áreas de cerrado sensu stricto sobre afloramentos rochosos, os indivíduos arbóreos e arbustivos encontram melhores condições de crescimento nos trechos com maior presença de substrato (Felfili \& Fagg 2007), em contraposição aos campos rupestres, que se caracterizam pela presença de vegetação predominantemente herbácea e arbustiva (Werneck \& Espírito-Santo 2002, Conceição \& Pirani 2007). Apesar das áreas rochosas serem impróprias para a agricultura, elas são ameaçadas pelas atividades de mineração, que removem rochas utilizadas principalmente para a construção civil, em serviços de acabamento residenciais e outros fins.

Estudos realizados em áreas de cerrado sensu stricto sobre afloramentos rochosos indicaram que existe uma semelhança em termos de diversidade dessa vegetação sobre substrato rochoso com o cerrado sobre outros tipos de solo, especialmente Latossolos e Neossolos Quartzarênicos, e a estrutura de sua vegetação varia de inferior (Amaral et al. 2006, Moura et al. 2007, Pinto et al. 2009) a similar (Felfili \& Fagg 2007). Com relação à composição florística, foi constatada a presença de espécies com ampla distribuição no Cerrado, consideradas generalistas, mas também de espécies endêmicas de áreas rupestres de altitude elevada (Amaral et al. 2006, Miranda et al. 2007, Moura et al. 2007, Pinto et al. 2009), de espécies preferenciais de solos mais férteis e também de espécies comuns com matas de galeria, ocorrendo em grotas (Felfili \& Fagg 2007, Pinto et al. 2009).

Este estudo parte da premissa de que apesar das diferenciações impostas pelo substrato, o cerrado sensu stricto sobre afloramentos rochosos estudado apresenta apenas um pequeno diferencial em espécies típicas, mas grande parte de sua flora é generalista e sua estrutura é similar ao cerrado sensu stricto que ocorre sobre os demais tipos de solo.

Este estudo tem como objetivos: 1) estudar a composição florística, a diversidade alfa e a estrutura do cerrado sensu stricto sobre afloramentos rochosos no Parque Estadual dos Pireneus; 2) analisar a distribuição das espécies em escala local, para detectar possíveis associações entre espécies; e 3) fazer uma análise comparativa do cerrado do Parque Estadual dos Pireneus com os cerrados sobre diferentes substratos em escala regional para detectar padrões fitogeográficos.

\section{Material e métodos}

Área de estudo - O Parque Estadual dos Pireneus dista 124 km de Goiânia (GO) e ocupa uma área de 2.822 ha no alto da Serra dos Pireneus. O parque situa-se às margens da rodovia BR-070 e seus limites que abrangem os Municípios de Cocalzinho, Corumbá e Pirenópolis. A altitude varia de $1.100 \mathrm{~m}$ a $1.395 \mathrm{~m}$, tendo como ponto culminante o Pico dos Pireneus (Agência Ambiental de Goiás \& Nativa 2002).

O clima da região, segundo Agência Ambiental de Goiás \& Nativa (2003), é do tipo Aw de Köppen, tropical úmido, caracterizado por duas estações bem definidas: uma seca, de abril a outubro, que corresponde ao outono/inverno, e outra úmida, com chuvas fortes, relativa ao período de primavera/ verão, nos meses de novembro a março (Agência Ambiental de Goiás \& Nativa 2003). Segundo a mesma agência, a precipitação anual média é da ordem de $1.500 \mathrm{~mm}$ e a temperatura média anual é de $22^{\circ} \mathrm{C}$. O parque está situado no domínio da sub-unidade morfoestrutural identificada como Planalto do Alto Tocantins-Paranaíba, e ocorrem rochas do Grupo Araxá, compostas de quartzito e uma associação quartzo-muscovita-xisto (Agência Ambiental de Goiás \& Nativa 2003). O solo predominante é do tipo Cambissolo, pobre em matéria orgânica, pouco profundo e cascalhento, em grande parte considerado como Litólico, com ocorrência de lajedos, blocos de rocha de tamanhos variados e afloramentos rochosos em toda sua extensão (Agência Ambiental de Goiás \& Nativa 2002). O parque possui basicamente cinco fitofisionomias: cerrado rupestre, cerrado de aluvião, campos, mata seca e mata de galeria (Agência Ambiental de Goiás \& Nativa 2003). Para o presente trabalho, avaliou-se a estrutura da comunidade arbustivo-arbórea em uma área de cerrado sensu stricto sobre afloramentos rochosos localizada no interior do Parque Estadual dos Pireneus, próxima ao portal de entrada do parque (1548'42"-47" S e 48 $52^{\prime} 40^{\prime \prime}-63^{\prime \prime} \mathrm{W}$, $1.310 \mathrm{~m}$ de altitude média).

Amostragem - Na paisagem ondulada da Serra dos Pireneus, foi selecionado um trecho contínuo de aproximadamente 190 ha, contendo picos e depressões, sem presença de cursos d'água, recoberto por cerrado sensu stricto (Eiten 1972) em sua maior parte. Neste trecho, as manchas de cerrado sensu stricto sobre afloramentos de rocha foram mapeadas, e a estas foi sobreposta uma malha de parcelas de $20 \times 50 \mathrm{~m}$, e dentre essas parcelas foram sorteadas 10 para a amostragem conforme metodologia adotada no "Projeto Biogeografia do Bioma Cerrado" para esta fisionomia (Felfili et al. 1994). Por meio de avaliação visual foi verificado que a maior parte da área das parcelas amostradas possui mais de $75 \%$ de cobertura de rochas, com ocorrência de solo entre as rochas ou sob a forma de uma delgada camada sobre as rochas. O diâmetro de todas as árvores foi medido com suta metálica, desde que apresentassem diâmetro do tronco igual ou superior a $5 \mathrm{~cm}$, tomado a $30 \mathrm{~cm}$ do solo. A distância de $30 \mathrm{~cm}$ do solo foi medida com o cabo da suta. Quando o tronco na altura do ponto de medição não era circular foram realizadas duas medidas 
cruzadas e foi calculada a média aritmética. Em árvores bifurcadas na base ou em caso de touceiras, cada tronco foi medido separadamente e assim computado para o cálculo da área basal. As alturas foram medidas com vara graduada. Devido às condições típicas de áreas com elevada declividade e presença de rochas, foi necessário adaptar as medições de altura e diâmetro em alguns indivíduos localizados entre rochas e em declives, objetivando obter a projeção vertical da copa ao solo para a mensuração das alturas sempre que possível, conforme adotado por Moura et al. (2007). Todos os indivíduos a partir do limite de inclusão foram identificados quando possível, até espécie, in loco ou por meio da coleta de material, cujas amostras foram posteriormente comparadas em herbários (UFG e UB) ou remetidas a especialistas. Todo o material coletado foi herborizado, etiquetado e incluído no acervo do herbário UFG.

Análise dos dados - Foi elaborada uma listagem de composição florística onde as famílias estão de acordo com o sistema do Angiosperm Phylogeny Group II (APG 2003). $\mathrm{O}$ índice de diversidade de Shannon na base $e$ foi utilizado para avaliar a diversidade florística da comunidade. Para a equabilidade foi calculado o índice de uniformidade de Pielou (Felfili \& Rezende 2003).

A fitossociologia da comunidade foi analisada por meio do cálculo da densidade (D), da freqüência $(F)$ e da dominância (Do) absolutas e relativas, bem como o valor de importância (VI), mediante a aplicação das fórmulas e conceitos contidos em Mueller-Dombois \& Ellenberg (1974) e Felfili \& Rezende (2003).

Para verificar a suficiência da amostragem em relação às variáveis quantitativas obtidas para a comunidade, foram determinados o erro padrão da média em percentagem (EP\%) e o intervalo de confiança (IC) a 95\% de probabilidade para densidade e para área basal das parcelas.

A análise de distribuição de diâmetros e alturas dos indivíduos amostrados na área foi realizada calculando o intervalo das classes diamétricas e de alturas por meio da fórmula de Spiegel (Felfili \& Rezende 2003).

Com o objetivo de identificar padrões na distribuição das espécies na comunidade foi realizada, mediante o uso do programa PC-ORD (McCune \& Mefford 1997), a classificação da vegetação por meio da aplicação do método TWINSPAN - Two-Way Indicator Species Analysis (Hill 1979), também conhecido como ACOD - Análise de Classificação-Ordenação Dicotomizada. Para a construção da matriz foi utilizada a variável densidade de espécies para cada parcela, com os níveis de corte $1,2,5$ e 10. O TWINSPAN foi também utilizado para classificar a vegetação de nove áreas de cerrado sensu stricto amostradas com a metodologia padronizada do Projeto Biogeografia do Bioma Cerrado (Felfili et al. 2004), além do presente estudo. Neste caso foi utilizada a variável densidade das espécies que apresentaram 10 ou mais indivíduos por área de estudo para a construção da matriz, e foram adotados os mesmos níveis de corte citados acima. O método é divisivo e classifica as parcelas em função de espécies indicadoras, preferenciais e não preferenciais (Hill 1979). As espécies não preferenciais são generalistas do ponto de vista de distribuição espacial, pois ocorrem em ambos os lados das dicotomias. Foram consideradas peculiares aos distintos ambientes aquelas indicadoras e preferenciais das divisões, e generalistas aquelas não preferenciais.

Os valores encontrados de densidade e dominância totais, índice de diversidade, equabilidade e riqueza florística, avaliada mediante a contagem dos números de espécies, gêneros e famílias registrados, foram comparados com os resultados obtidos em outros levantamentos.

\section{Resultados}

Composição florística e diversidade alfa - Um total de 35 famílias, 51 gêneros e 65 espécies foi encontrado na área de estudo, das quais 25 famílias foram representadas por apenas uma espécie mostrando uma concentração da riqueza em poucas famílias, tendência encontrada para a flora arbórea da vegetação de cerrado sensu stricto (Nogueira et al. 2001, Felfili et al. 2002). As famílias mais ricas em espécies foram: Myrtaceae, com oito espécies, Fabaceae, com sete, e Melastomataceae, com seis, representando $32 \%$ do total de espécies encontradas. Myrtaceae, Melastomataceae, Fabaceae e Vochysiaceae foram as famílias que exibiram destaque em densidade, com 184, 90, 85 e 79 indivíduos, respectivamente. A diversidade alfa foi elevada com o índice de Shannon $(H)$ de 3,65 nats ind ${ }^{-1}$ e a equabilidade de Pielou $(J) 0,87$.

Estrutura comunitária - A densidade foi de 1.105 ind ha ${ }^{-1}$ e a área basal de $11,03 \mathrm{~m}^{2} \mathrm{ha}^{-1}$. O erro padrão da média em percentagem e o intervalo de confiança para a média das parcelas foram de $7,17 \%$ e IC $=$ $(1105-155 \leq \mathrm{M} \leq 1105+155)=95 \%$ para a densidade e $7,79 \%$ e IC $=(11-1,6 \leq \mathrm{M} \leq 11+1,6)=95 \%$ para a área basal, sugerindo uma amostragem representativa da área (Campos \& Leite 2006).

Poucas espécies compuseram grande parte da estrutura do cerrado, as doze primeiras espécies em VI (tabela 2) foram responsáveis por mais de $50 \%$ da dominância e da densidade totais.

No total, 23 espécies apresentaram VI menor que $10 \%$ do maior valor encontrado, representando $13,9 \%$, $4,6 \%$ e $6,03 \%$ da freqüência, dominância e densidade totais, respectivamente. Isto indica um número elevado de espécies pouco comuns nesta área, com baixa densidade, o que é um padrão comum no Cerrado (Felfili \& Fagg 2007).

Alchornea triplinervia foi a única espécie observada em todas as parcelas e pode ser considerada como amplamente dispersa nesta localidade. Esta espécie, 
juntamente com Schwartzia adamantium e Siphoneugena densiflora somaram 25,45\% da dominância, apresentando indivíduos de grande porte.

Os indivíduos mortos ainda em pé representaram $24,52 \%$ do VI, $12 \%$ do total dos indivíduos amostrados, $9,12 \%$ da área basal e ocorreram em todas as parcelas. Estes são valores elevados quando comparados a outros estudos desenvolvidos em cerrado sensu stricto (tabela 1).

A curva da distribuição de diâmetros dos indivíduos vivos apresentou uma tendência ao formato de J-invertido (figura 1), com $46 \%$ das árvores pertencentes à primeira classe de diâmetro. Na distribuição do número de espécies por classes diamétricas verifica-se que $85 \%$ das espécies registradas encontram-se na primeira classe diamétrica, caindo para 32\% na quarta classe. Assim, percebe-se que quase a totalidade das espécies está recrutando e que o formato de J-invertido encontrado pode ser explicado pelo recrutamento e não apenas pelo pequeno porte inerente de várias espécies do cerrado que ocorrem apenas nas menores classes diamétricas (Felfili 2001). Somente 13 indivíduos (1,33\%), pertencentes a oito espécies, apresentaram diâmetro superior a $30 \mathrm{~cm}$ : Alchornea triplinervia, Callisthene major, Clusia burchellii, Emmotum nitens, Schwartzia adamantium, Ocotea pomaderroides, Myrsine guianensis e Sclerolobium paniculatum.

Com relação à altura dos indivíduos a mediana encontrada foi de $3,18 \mathrm{~m}$. Alchornea triplinevia e

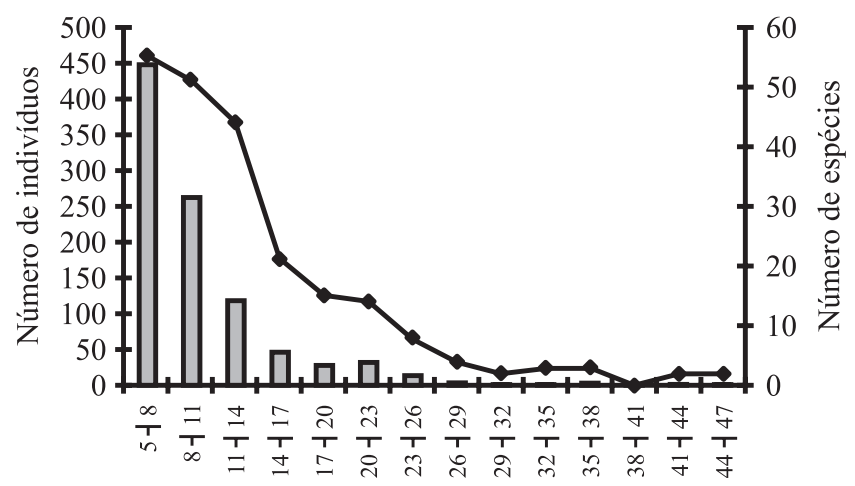

Classes de diâmetro $(\mathrm{cm})$

Figura 1. Distribuição por classes de diâmetro dos indivíduos vivos e espécies amostrados em área de cerrado sensu stricto sobre afloramentos rochosos no Parque Estadual dos Pireneus, Goiás. (Coluna = indivíduos; linha $=$ espécies $)$.

Figure 1. Distribution of the number of individuals and species by diameter class sampled in an area of cerrado sensu stricto on rock outcrops of the Pireneus State Park, Goiás. $($ Column $=$ individuals; line $=$ species $)$.
Vochysia thyrsoidea foram as espécies que atingiram maior altura, apresentando uma grande variação no porte de seus indivíduos, desde aproximadamente $2 \mathrm{~m}$ até 9,5 m. Emmotum nitens, espécie comum nos cerradões (Felfili et al. 1994, Marimon \& Lima 2001), apresentou apenas indivíduos de grande porte, com altura mínima de 5,34 m, média de $6,27 \mathrm{~m}$ e máxima de 7,84 m. Sclerolobium paniculatum e Ficus insipida também demonstraram o mesmo padrão de Emmotum nitens.

Padrões de distribuição das espécies em nível local (Parque Estadual dos Pireneus) e regional - A primeira divisão da classificação em nível local, ou seja, das áreas de Pirenópolis (figura 2) apresentou autovalor de 0,3198, sendo a dicotomia definida pela presença, de um lado, de espécies típicas de cerrado sensu stricto como Miconia pohliana, Plenckia populnea e Roupala montana, e de outro de espécies mais características de mata de galeria, ocorrendo nessa área em grotas ou fendas entre rochas, como Callisthene major, Licania kunthiana e Matayba guianensis.

A classificação em nível regional incluiu 10 áreas de cerrado sensu stricto (figura 3) gerando quatro divisões. Os autovalores encontrados foram superiores a 0,3 , o que indica divisões fortes (Hill 1979). Detalhes destas áreas podem ser encontrados na tabela 1. A área de Pirenópolis foi separada das demais logo na primeira divisão. A dicotomia foi definida principalmente, por um lado, por espécies características deste cerrado de

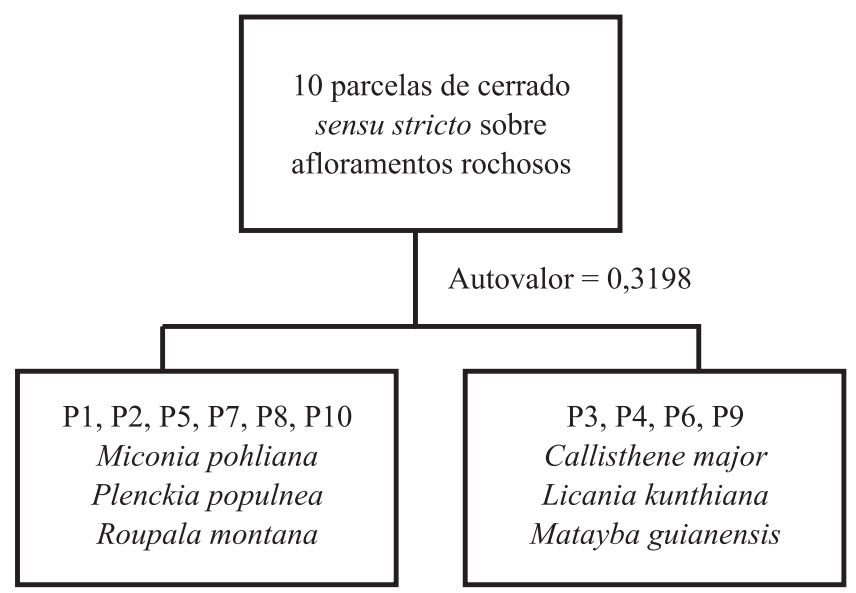

Figura 2. Classificação pelo método TWINSPAN das parcelas amostradas em área de cerrado sensu stricto sobre afloramentos rochosos no Parque Estadual dos Pireneus, Goiás.

Figure 2. TWINSPAN classification for plots sampled in area of cerrado sensu stricto on rocky outcrops in the Pireneus State Park, Goiás. 


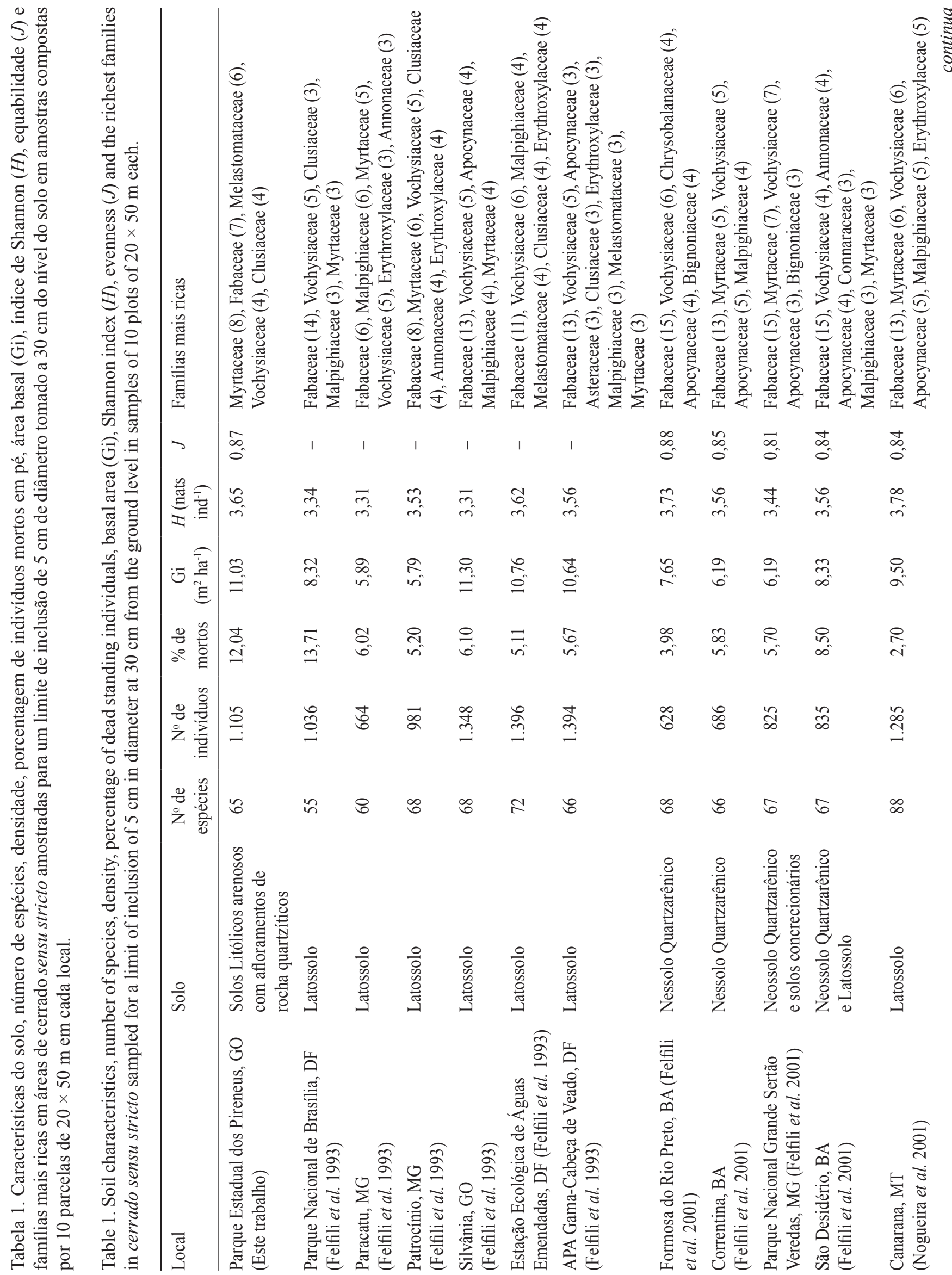




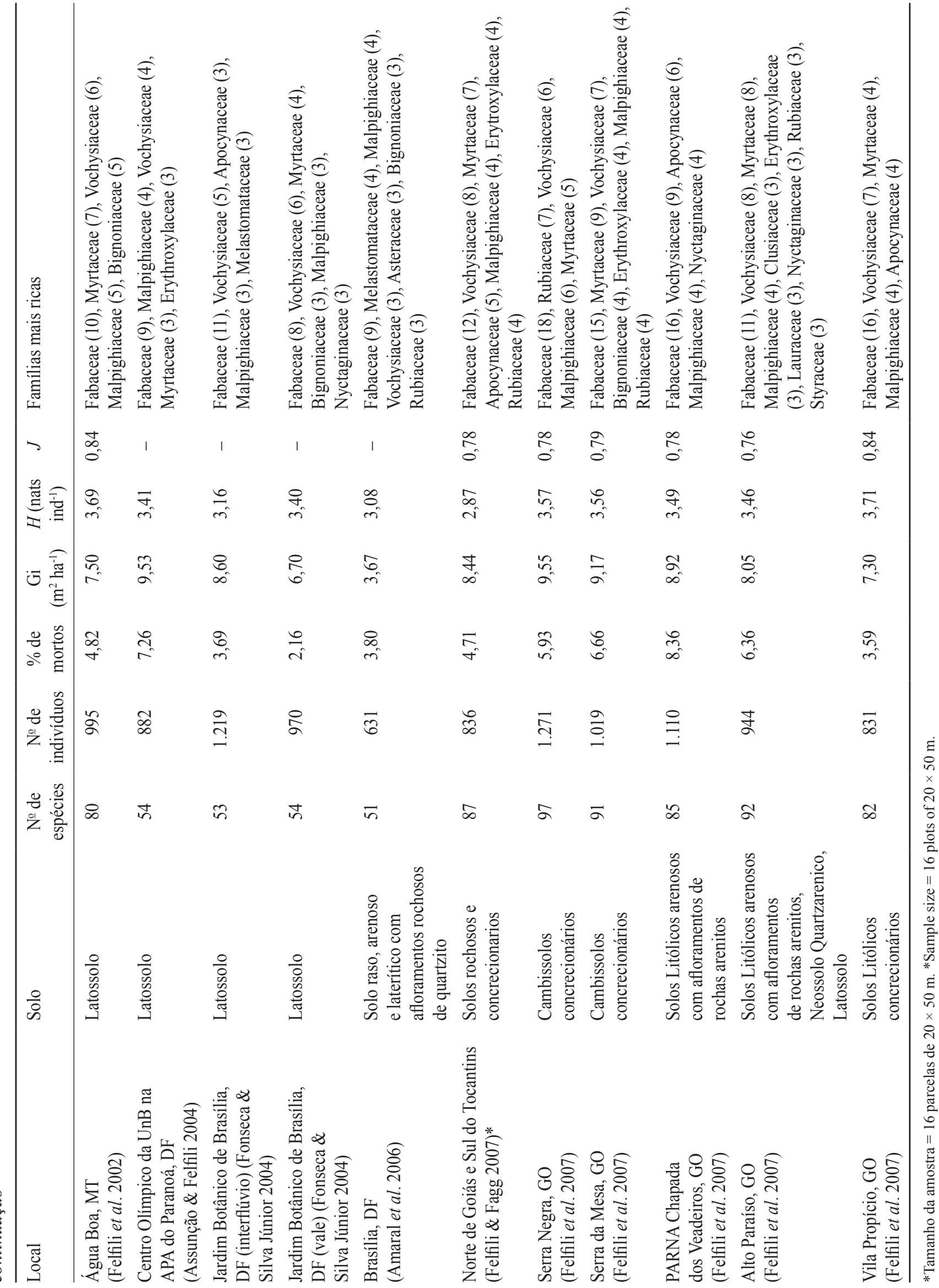




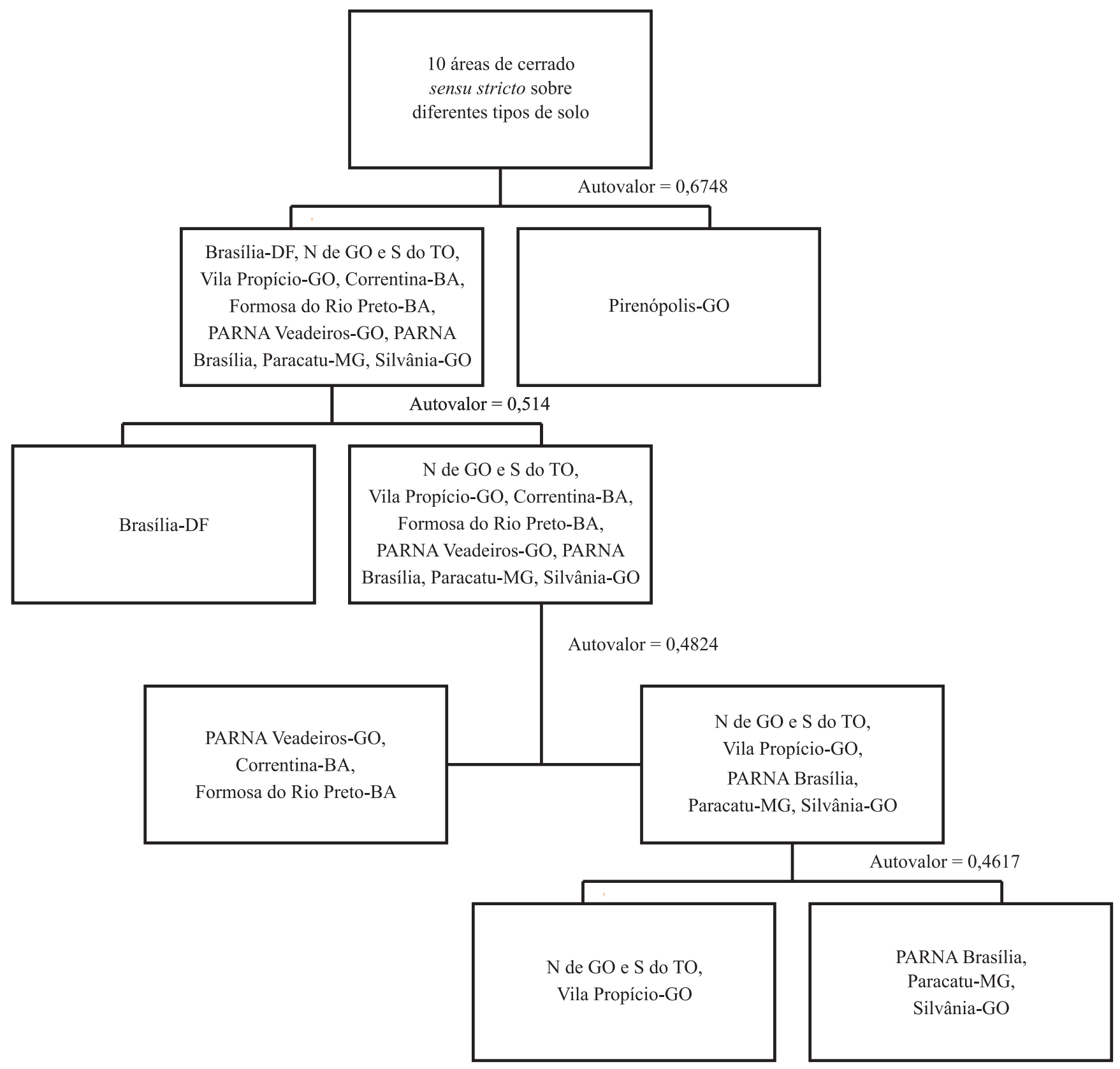

Figura 3. Classificação pelo método TWISNPAN de dez áreas de cerrado sensu stricto no Brasil central.

Figure 3. TWINSPAN classification of ten areas of cerrado sensu stricto in central Brazil.

Pirenópolis, como Alchornea triplinervia, Tibouchina papyrus, Schwartzia adamantium e Clusia burchelli, e de outro por espécies generalistas do Cerrado como Qualea parviflora, Qualea grandiflora, Byrsonima verbascifolia, Byrsonima crassa, Vochysia rufa, Ouratea hexasperma e Pouteria ramiflora (Ratter et al. 2003). A segunda divisão separou a área de Brasília, definida como cerrado rupestre por Amaral et al. (2006), das outras áreas. A terceira divisão separou as áreas mais arenosas:
Correntina e Formosa do Rio Preto, que são áreas de Neossolo Quartzarênico e Parque Nacional da Chapada dos Veadeiros, cujas parcelas estavam localizadas em solos litólicos arenosos com afloramento de rochas arenitos. A quarta e última dicotomia separou as áreas do Parque Nacional de Brasília, Paracatu e Silvânia, que foram áreas associadas a Latossolos, das áreas de Vila Propício e do Norte de Goiás e Sul do Tocantins, associadas a solos rochosos e concrecionários. 


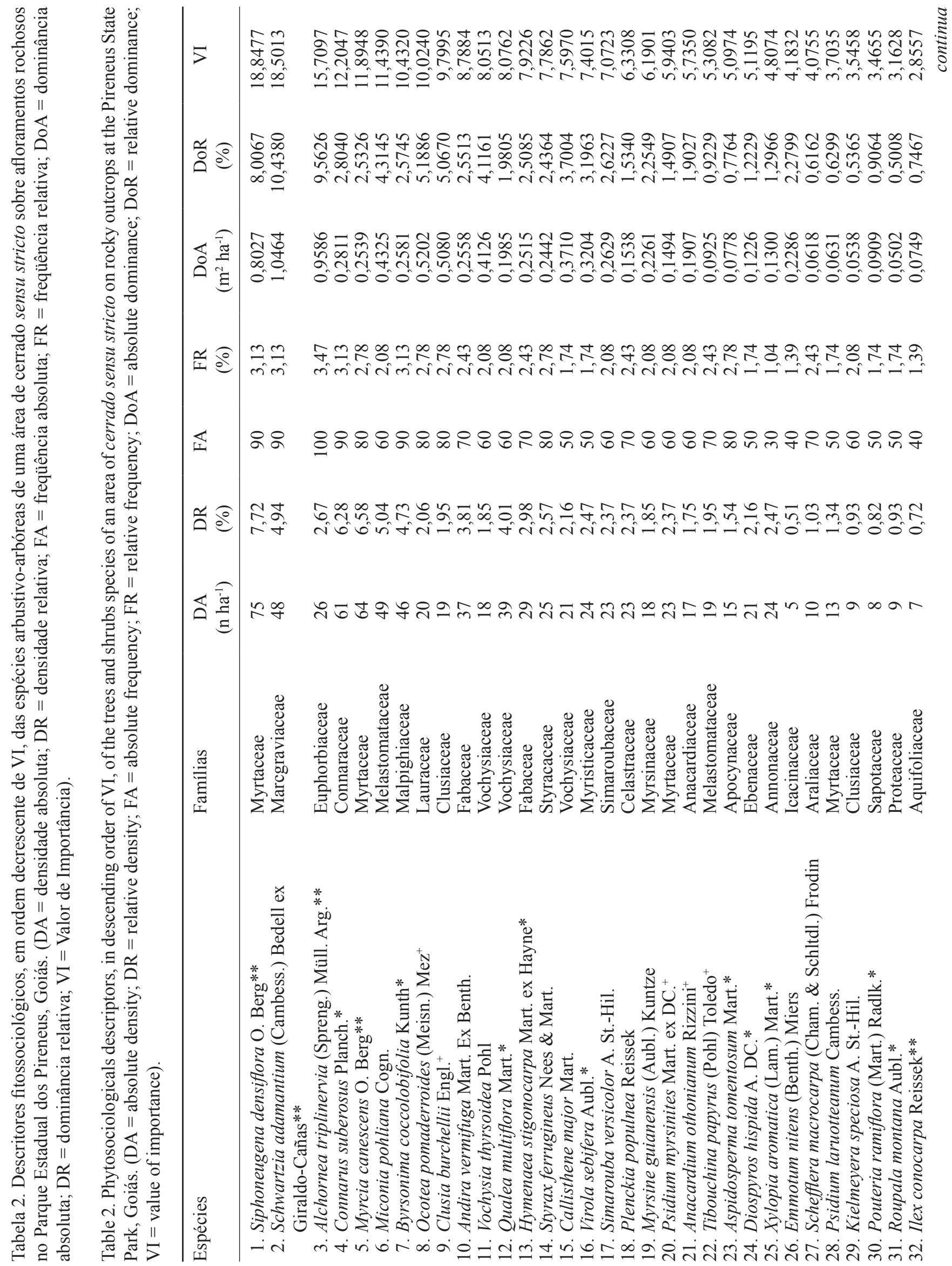




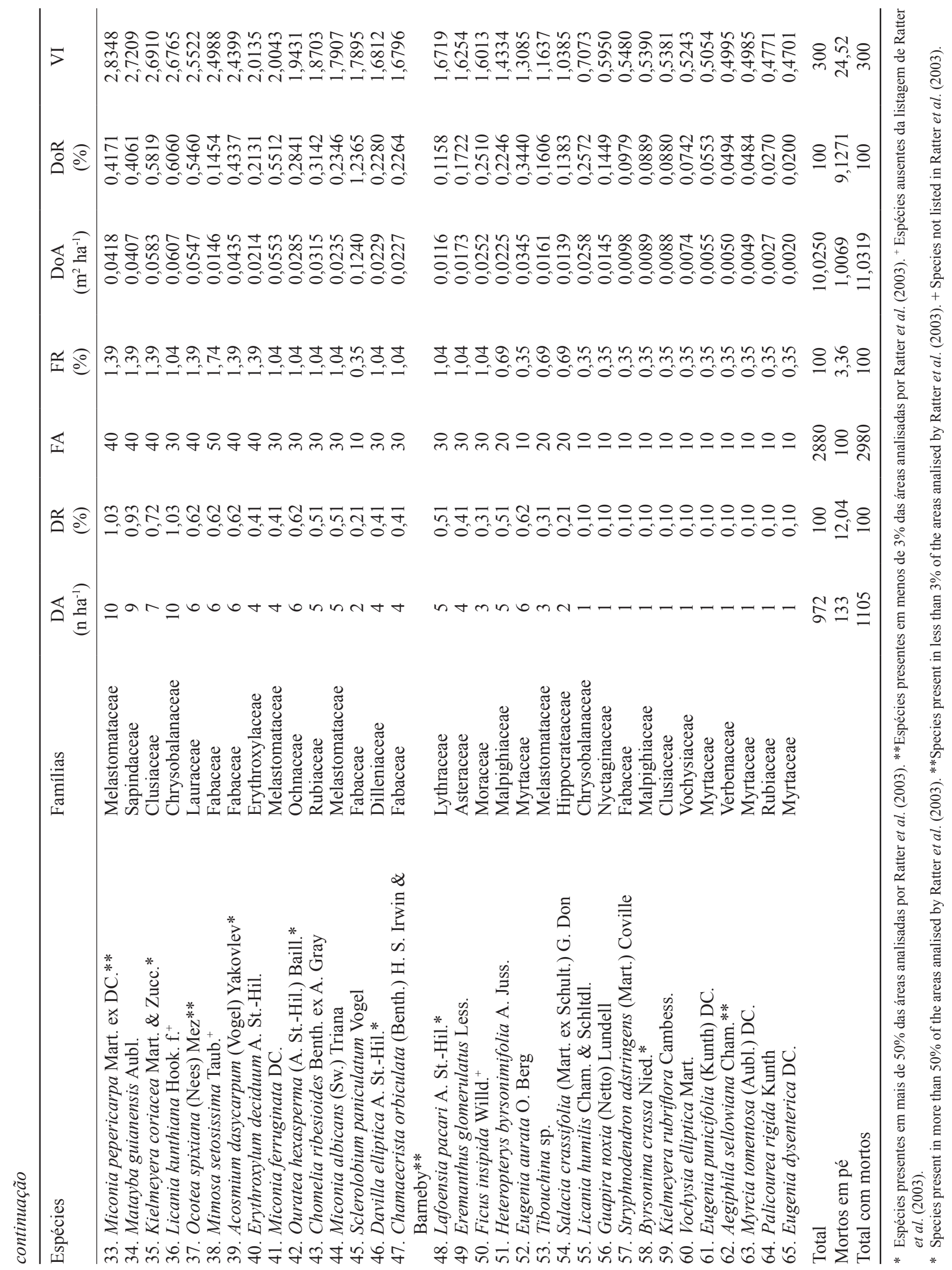




\section{Discussão}

Composição florística e diversidade alfa - $\mathrm{O}$ cerrado sensu stricto em afloramentos rochosos na Serra dos Pireneus é rico, com elevada diversidade alfa, comparável com valores encontrados para esta fisionomia sobre Latossolos profundos e bem drenados (tabela 1), reforçando a tendência encontrada por alguns autores (Amaral et al. 2006, Felfili \& Fagg 2007, Felfili et al. 2007, Miranda et al. 2007, Moura et al. 2007, Pinto et al. 2009). Uma diferenciação encontrada em nível de família foi a riqueza em espécies da família Myrtaceae, pois em geral Fabaceae costuma ser a mais rica (tabela 1) nas condições de cerrado. Dezesseis espécies (tabela 2) consideradas de distribuição ampla no Cerrado por Ratter et al. (2003), por ocorrerem em mais de $50 \%$ de 376 áreas estudadas de cerrado sensu lato e savanas amazônicas, ocorreram neste trabalho e foram consideradas como espécies generalistas do Cerrado. Dentre estas generalistas estão Connarus suberosus e Byrsonima coccolobifolia, que ocupam a 4 e a 7 posição em VI neste trabalho, respectivamente. Por outro lado, nove espécies encontradas em Pirenópolis foram listadas por Ratter et al. (2003) em menos de 3\% dos locais, e outras oito não apareceram na referida listagem (tabela 2). Assim, pode-se inferir que tais espécies possuem distribuição restrita no Cerrado ou são especialistas de certos ambientes.

Dentre todas as espécies encontradas neste trabalho, apenas Eremanthus glomerulatus, Licania humilis, Eugenia punicifolia e Schwartzia adamantium são citadas na listagem da flora vascular do Cerrado de Mendonça et al. (1998) com ocorrência também em áreas rupestres, mais especificamente, campos rupestres lato sensu. De acordo com a referida listagem, Clusia burchellii (9a posição em VI) ocorre em mata seca e cerrado, mas não é muito mencionada na literatura, podendo ser considerada pouco comum ou rara no Cerrado. Em um estudo sobre a família Marcgraviaceae do Estado de Goiás, Peixoto (1985) conclui que Schwartzia adamantium (2 posição em VI no presente trabalho) é nativa de campos rupestres, ocorrendo em altitude elevada. Tibouchina papyrus (22 posição em VI) possui distribuição restrita ao Estado de Goiás, com ocorrência observada na Serra dos Pireneus, na Serra Dourada e na Chapada dos Veadeiros (Rizzo 1970, Munhoz \& Proença 1998).

Estrutura comunitária - A concentração dos parâmetros estruturais em poucas espécies verificada neste cerrado em afloramento rochoso tem sido encontrada para outras áreas de cerrado. Felfili et al. (2004), ao analisarem a estrutura comunitária de 15 localidades de cerrado sensu stricto, encontraram como padrão principal um pequeno número de espécies (cerca de 10) compreendendo mais de $50 \%$ da densidade e da área basal por local. Este mesmo padrão foi encontrado por Amaral et al. (2006), Miranda et al. (2007), Moura et al. (2007) e Pinto et al. (2009) em áreas de cerrado rupestre no Distrito Federal e em Goiás, e por Felfili \& Fagg (2007) em cerrado sensu stricto sobre solos rochosos no Norte de Goiás e no Sul do Tocantins. Portanto, a concentração da riqueza em poucas famílias e da densidade em poucas espécies é uma característica da vegetação de cerrado sensu stricto.

A área basal encontrada neste cerrado sobre rochas coincide com valores comumente encontrados para cerrado sensu stricto em Latossolos e demais tipos de solos (tabela 1). A área basal de tronco, em geral, apresenta correlação com a cobertura de copas, permitindo inferências (Cain \& Castro 1959, Brunig 1983). Neste caso infere-se que se neste cerrado sobre afloramentos rochosos a área basal é equivalente à do cerrado sensu stricto, a cobertura de copas poderá ser também similar, de modo que este cerrado apresentará cobertura maior do que os $20 \%$ atribuídos por Ribeiro $\&$ Walter (1998) para cerrado rupestre.

O percentual de indivíduos mortos ainda em pé para densidade, freqüência, dominância e VI é elevado, sugerindo a ocorrência de distúrbios recentes sendo, portanto, um indicador de perturbações conforme sugerido por Felfili \& Silva Júnior (1992). Uma dinâmica elevada resultante do estresse sofrido pelas plantas no ambiente rochoso, ou ainda uma decomposição de madeira mais lenta devido à escassez de substrato, o que manteria as árvores mortas em pé por mais tempo, podem ser conseqüência do ambiente rochoso. Porém, tais suposições necessitam de estudos adicionais para serem comprovadas.

O formato de J-invertido apresentado pela curva de distribuição de diâmetros é um padrão considerado comum em florestas tropicais (Felfili et al. 1997), mas se estende ao cerrado, como demonstram alguns estudos feitos no Distrito Federal (Felfili \& Silva Júnior 1988, Andrade et al. 2002, Assunção \& Felfili 2004, Amaral et al. 2006), na Chapada do Espigão Mestre do São Francisco, BA e MG (Felfili 2001), entre outros. Este padrão de distribuição de diâmetros, associado à distribuição de espécies por classe de diâmetro, indica uma tendência para um equilíbrio entre recrutamento e mortalidade, uma vez que a maior riqueza de espécies está nas classes de maior abundância.

Com base nas análises de diâmetro e altura, percebe-se que esta comunidade, apesar dos afloramentos rochosos, apresenta estrutura similar às comunidades de cerrado sensu stricto sobre outros tipos de solo. 
Padrões de distribuição das espécies em nível local (Parque Estadual dos Pireneus) e regional - O padrão encontrado na classificação das parcelas do Parque Estadual dos Pireneus, apresentando divisões onde espécies de mata de galeria caracterizaram alguns agrupamentos em contraposição às espécies de cerrados em outros, foi também encontrado por Felfili \& Fagg (2007) em áreas de cerrado sobre rochas no Norte de Goiás e no Sul do Tocantins. Os autores argumentam que a quantidade de matéria orgânica acumulada entre as rochas é suficiente para suportar espécies que ocorrem predominantemente em solos mais férteis e que a presença de grotas nos solos declivosos permite a passagem e o acúmulo de água, dando suporte à ocorrência de espécies higrófilas. Assim, pode-se inferir que a distribuição de plantas lenhosas neste cerrado sensu stricto sobre afloramentos rochosos pode ser influenciada pela ocorrência de diferentes microhabitats ocasionados pela presença e disposição de rochas, que ocasionariam maior ou menor acúmulo de matéria orgânica, conforme relatado para outras fisionomias rochosas, como campo rupestre (Conceição \& Pirani 2005) e campo de altitude (Medina et al. 2006).

Dentre as espécies não preferenciais, que ocorrem indiscriminadamente nas áreas do Parque Estadual dos Pireneus, estão espécies de ampla distribuição no Cerrado, como Qualea multiflora e Byrsonima coccolobifolia, mas também Schwartzia adamantium, Clusia burchellii e Alchornea triplinervia, espécies de distribuição restrita no Cerrado, mas características da área que é rochosa na sua totalidade. Tal afirmação é corroborada pela primeira divisão da classificação realizada para as 10 áreas de cerrado, que separou o Parque Estadual dos Pireneus de todas as outras áreas, tendo estas três espécies preferenciais.

A separação da área de Pirenópolis de todas as outras na primeira divisão e da área de cerrado rupestre de Brasília na segunda divisão demonstra que estas áreas apresentam composição florística e densidade de espécies peculiares, que as diferenciam das demais áreas. Tal explicação é reforçada ao se verificar o número reduzido de espécies não preferenciais destas duas divisões: apenas Byrsonima coccolobifolia para a primeira divisão e Byrsonima verbascifolia, Qualea grandiflora e Ouratea hexasperma para a segunda. As demais divisões parecem estar relacionadas ao tipo de solo nas áreas: as áreas mais arenosas foram separadas das demais na terceira divisão, e a quarta divisão separou as áreas de Latossolo de duas áreas com presença de rochas.

Conclusão - O cerrado sensu stricto sobre afloramentos rochosos do Parque Estadual dos Pireneus apresenta uma composição florística característica, composta por espécies provavelmente selecionadas pela pequena profundidade do solo e pelo substrato rochoso, como Schwartzia adamantium, Alchornea triplinervia e Clusia burchellii, assim como por espécies generalistas das fisionomias de cerrado e também espécies mais comuns em mata de galeria. Sua diversidade é elevada e sua estrutura é similar àquela descrita para a vegetação de cerrado sensu stricto.

Agradecimentos - À Capes pela bolsa de mestrado da primeira autora, ao CNPq pela bolsa de produtividade em pesquisa para a terceira autora, a todos que colaboraram nos trabalhos de campo, à Agência Ambiental de Goiás pela permissão para a realização da pesquisa no parque.

\section{Referências bibliográficas}

AGÊNCIA AMBIENTAL DE GOIÁS \& NATIVA. 2002. Parque Estadual dos Pireneus - Relatório Inicial: contextualização do parque. Agência Ambiental de Goiás, Goiânia.

AGÊNCIA AMBIENTAL DE GOIÁS \& NATIVA. 2003. Parque Estadual da Serra dos Pireneus - Relatório Parcial: consolidação das pesquisas de campo. Agência Ambiental de Goiás, Goiânia.

AMARAL, A.G., PEREIRA, F.F.O. \& MUNHOZ, C.B.R. 2006. Fitossociologia de uma área de cerrado rupestre na Fazenda Sucupira, Brasília, DF. Cerne 12:350-359.

ANDRADE, L.A.Z., FELFILI, J.M. \& VIOLATTI, L. 2002. Fitossociologia de uma área de cerrado denso na RECOR-IBGE, Brasília, DF. Acta Botanica Brasilica 16:225-240.

APG. 2003. An update of the angiosperm phylogeny group classication for the orders and families of flowering plants: APG II. Botanical Journal of the Linnean Society 141:399-436.

ASSUNÇÃO, S.L. \& FELFILI, J.M. 2004. Fitossociologia de um fragmento de cerrado sensu stricto na APA do Paranoá, DF, Brasil. Acta Botanica Brasilica 18:903-909.

BRUNIG, E.F. 1983. Vegetation structure and growth. In Tropical rain forest ecosystems: structure and function. (F.B. Golley, ed.). Elsevier Scientific Publishing Company, Amsterdam, p.49-75.

CAIN, S.A. \& CASTRO, G.M.O. 1959. Manual of vegetatation analysis. Harper \& Brothers, New York.

CAMPOS, J.C.C. \& LEITE, H.G. 2006. Mensuração florestal: perguntas e respostas. Editora da UFV, Viçosa.

CONCEIÇÃO, A.A. \& PIRANI, J.R. 2005. Delimitação de habitats em campos rupestres na Chapada Diamantina, Bahia: substratos, composição florística e aspectos estruturais. Boletim de Botânica da Universidade de São Paulo 23:85-111. 
CONCEIÇÃO, A.A. \& PIRANI, J.R. 2007. Diversidade em quatro áreas de campos rupestres na Chapada Diamantina, Bahia, Brasil: espécies distintas, mas riquezas similares. Rodriguésia 58:193-206.

EITEN, G. 1972. The cerrado vegetation of Brazil. Botanical Review 38:201-341.

FELFILI, J.M. 2001. Distribuição de diâmetros de quatro áreas de cerrado sensu stricto na Chapada do Espigão Mestre do São Francisco. In Biogeografia do bioma cerrado: estudo fitofisionômico na Chapada do Espigão Mestre do São Francisco (J.M. Felfili \& M.C. Silva Júnior, orgs.). Universidade de Brasília, Faculdade de Tecnologia, Departamento de Engenharia Florestal, Brasília, p.57-61.

FELFILI, J.M. \& FAGG, C.W. 2007. Floristic composition, diversity and structure of the "cerrado" sensu stricto on rocky soils in northern Goiás and southern Tocantins, Brazil. Revista Brasileira de Botânica 30:375-385.

FELFILI, J.M. \& REZENDE, R.P. 2003. Conceitos e métodos em fitossociologia. Universidade de Brasília, Departamento de Engenharia Florestal, Brasília.

FELFILI, J.M. \& SILVA JÚNIOR, M.C. 1988. Distribuição dos diâmetros numa faixa de Cerrado na Fazenda Água Limpa (FAL) em Brasília, DF. Acta Botanica Brasilica 2:85-104.

FELFILI, J.M. \& SILVA JÚNIOR, M.C. 1992. Floristic composition, phytosociology and comparison of cerrado and gallery forest at Fazenda Água Limpa, Federal District, Brazil. In Nature and dynamics of forestsavanna boundaries (P.A. Furley, J. Proctor \& J.A. Ratter, eds.). Chapman \& Hall, London, p.393-416.

FELFILI, J.M. \& SILVA JÚNIOR, M.C. 2001. Biogeografia do bioma cerrado: estudo fitofisionômico na Chapada do Espigão Mestre do São Francisco. Universidade de Brasília, Faculdade de Tecnologia, Departamento de Engenharia Florestal, Brasília.

FELFILI, J.M., SILVA JÚNIOR, M.C., REZENDE, A.V., MACHADO, J.W.B., WALTER, B.M.T., NOGUEIRA, P.E. \& HAY, J.D. 1993. Análise comparativa da florística e fitossociologia da vegetação arbórea do cerrado sensu stricto na Chapada Pratinha, DF, Brasil. Acta Botanica Brasilica 6:27-43.

FELFILI, J.M., SILVA JUNIOR, M.C., REZENDE, A.V., MACHADO, J.W.B., NOGUEIRA, P.E. \& WALTER, S.M.T. 1994. Projeto Biogeografia do Bioma Cerrado: vegetação e solos. Cadernos de Geociências 12:84114.

FELFILI, J.M., SILVA JÚNIOR, M.C., REZENDE, A.V., NOGUEIRA, P.E., WALTER, B.M.T., FELFILI, M.C., SILVA, M.A. \& ENCINAS, J.I. 1997. Comparação florística e fitossociológica do cerrado nas Chapadas Pratinha e dos Veadeiros. In Contribuição ao conhecimento ecológico do Cerrado (L.L. Leite, C.H. Saito, eds.) Editora Universidade de Brasília, Brasília, p.6-11.
FELFILI, J.M., SILVA JÚNIOR, M.C, SEVILHA, A.C., REZENDE, A.V., NOGUEIRA, P.E., WALTER, B.M., SILVA, F.C. \& SALGADO, M.A.S. 2001. Fitossociologia da vegetação arbórea. In Biogeografia do bioma cerrado: estudo fitofisionômico na Chapada do Espigão Mestre do São Francisco (J.M. Felfili \& M.C. Silva Júnior, orgs.). Universidade de Brasília, Faculdade de Tecnologia, Departamento de Engenharia Florestal, Brasília, p.35-56.

FELFILI, J.M., NOGUEIRA, P.E., SILVA JÚNIOR, M.C., MARIMON, B.S. \& DELITTI, W.B.C. 2002. Composição florística do cerrado sentido restrito no município de Água Boa, MT. Acta Botanica Brasilica 16:103-112.

FELFILI, J.M., SILVA JÚNIOR, M.C., SEVILHA, A.C., FAGG, C.W., WALTER, B.M.T., NOGUEIRA, P.E. \& REZENDE, A.V. 2004. Diversity, floristic and structural patterns of cerrado vegetation in Central Brazil. Plant Ecology 175:37-46.

FELFILI, J.M., REZENDE, A.V. \& SILVA JÚNIOR, M.C. 2007. Biogeografia do Bioma Cerrado: vegetação e solos da Chapada dos Veadeiros. Editora da Universidade de Brasília, Brasília.

FONSECA, M.S. \& SILVA JÚNIOR, M.C. 2004. Fitossociologia e similaridade florística entre trechos de cerrado sentido restrito em interflúvio e em vale no Jardim Botânico de Brasília, DF. Acta Botanica Brasilica 18:19-29.

HILL, M.O. 1979. TWINSPAN - a FORTRAN program for arranging multivariate data in a ordered two-way table by classification of individuals and attributes. Cornell University, Ithaca.

MARIMON, B.S. \& LIMA, E.S. 2001. Caracterização fitofisionômica e levantamento florístico preliminar no Pantanal dos Rios Mortes - Araguaia, Cocalinho, Mato Grosso, Brasil. Acta Botanica Brasilica 15:213-229.

MCCUNE, B. \& MEFFORD, M.J. 1997. PC-ORD for Windows: Multivariate Analysis of Ecological Data, version 3.17. MjM Software, Oregon.

MEDINA, B.M.O., RIBEIRO, K.T. \& SCARANO, F.R. 2006. Plant-plant and plant-topography interactions on a rock outcrop at high altitude in southeastern Brazil. Biotropica 38:1-7.

MENDONÇA, R.C., FELFILI, J.M., WALTER, B.M.T., SILVA JÚNIOR, M.C., REZENDE, A.V., FILGUEIRAS, T.S. \& NOGUEIRA, P.E. 1998. Flora vascular do cerrado. In Cerrado: ambiente e flora (S.M. Sano \& S.P. Almeida, eds.). Embrapa, Planaltina, p.289-556.

MIRANDA, S.C., SILVA JÚNIOR, M.C. \& SALLES, L.A. 2007. A comunidade lenhosa de cerrado rupestre na Serra Dourada, Goiás. Heringeriana 1:43-53.

MOURA, I.O., GOMES-KLEIN, V.L., FELFILI, J.M. \& FERREIRA, H.D. 2007. Fitossociologia da comunidade lenhosa de uma área de cerrado rupestre no Parque Estadual dos Pireneus, Pirenópolis, Goiás. Revista de Biologia Neotropical 4:83-100. 
MUELLER-DOMBOIS, D. \& ELLENBERG, H. 1974. Aims and methods of vegetation ecology. John Wiley \& Sons, New York.

MUNHOZ, C.B.R. \& PROENÇA, C.E.B. 1998. Composição florística do município de Alto Paraíso de Goiás na Chapada dos Veadeiros. Boletim do Herbário Ezequias Paulo Heringer 3:102-150.

NOGUEIRA, P.E., FELFILI, J.M., SILVA JÚNIOR, M.C., DELITTI, W. \& SEVILHA, A. 2001. Composição florística e fitossociologia de uma cerrado sentido restrito no município de Canarana, MT. Boletim do Herbário Ezequias Paulo Heringer 8:28-43.

PEIXOTO, A.B.F. 1985. Marcgraviaceae. In Flora do Estado de Goiás: Coleção Rizzo (J.A. Rizzo, coord.). Editora da Universidade Federal de Goiás, Goiânia, v.5, p.1-32.

PINTO, J.R.R., LENZA, E. \& PINTO, A.S. 2009. Composição florística e estrutura da vegetação arbustivo-arbórea em um cerrado rupestre, Cocalzinho de Goiás, Goiás. Revista Brasileira de Botânica 32: 1-10.
RATTER, J.A., BRIDGEWATER, S. \& RIBEIRO, J.F. 2003. Analysis of the floristic composition of the Brazilian cerrado vegetation III: comparison of the wood vegetation of 376 areas. Edinburgh Journal of Botany 60:57-109.

REATTO, A., CORREIA, J.R. \& SPERA, S.T. 1998. Solos do Bioma Cerrado: aspectos pedológicos. In Cerrado: ambiente e flora (S.M. Sano \& S.P. Almeida, eds.). Embrapa, Planaltina, p.47-86.

RIBEIRO, J.F. \& WALTER, B.M.T. 1998. Fitofisionomias do Bioma Cerrado. In Cerrado: ambiente e flora (S.M. Sano \& S.P. Almeida, eds.). Embrapa, Planaltina, p.89-166.

RIZZO, J.A. 1970. Contribuição ao conhecimento da Flora de Goiás - Área na Serra Dourada. Tese de livre-docência, Universidade Federal de Goiás, Goiânia.

WERNECK, M.S. \& ESPÍRITO-SANTO, M.M. 2002. Species diversity and abundance of vascular epiphytes on Vellozia piresiana in Brazil. Biotropica 34:51-57. 